\section{Kidney \\ Blood Pressure Research}

\title{
Blood Pressure Characteristics in Moderate to Severe Renal Insufficiency
}

\author{
Zheyou Wu $\mathrm{W}^{\mathrm{a}, \mathrm{b}}$ Xiaohong Wu $\mathrm{W}^{\mathrm{a}}$ Fang Xing ${ }^{\mathrm{a}, \mathrm{b}}$ Shanjun Zhou ${ }^{\mathrm{c}}$ Benyan Luo \\ Lihong Wanga,d
}

${ }^{a}$ The First Affiliated Hospital, College of Medicine, Zhejiang University; ${ }^{b}$ Ningbo Beilun People's Hospital; ' Ningbo Daxie Development zone Hospital; dDepartment of Cardiovascular Sciences, Zhejiang Provincial People's Hospital, Hangzhou Province, P.R. China

\section{Key Words}

Hypertension - Chronic kidney disease - Ambulatory blood pressure monitoring - Stage classification $\cdot$ Blood pressure load $\cdot$ Heart rate

\begin{abstract}
Background/Aims: Ambulatory blood pressure monitoring (ABPM) in chronic kidney disease (CKD) patients has been extensively studied, but few investigations have attempted to relate $A B P M$ with CKD stages. The objectives of this article were to compare ABPM parameters for the diagnosis and treatment determination of CKD with daytime clinic blood pressure (BP) measurements. We also investigated BP and renal injury in combined hypertension and CKD. We supposed ABPM was important in combined hypertension and CKD. Methods: We compared ABPM in hypertension patients, including 152 patients with combined hypertension and CKD. Patients with combined hypertension and CKD were grouped according to severity into stages 1 through 3 (Stage 1-3) and stages 4 and 5 (Stage 4-5). Results: In the Stage 4-5 group, systolic BP (SBP) (daytime, nighttime and $24 \mathrm{~h}$ mean), diastolic BP (DBP), pulse pressure and SBP standard deviations (SD) (daytime and $24 \mathrm{~h}$ ) were higher. SBP and DBP loads were significantly higher in the Stage 4-5 group. The nighttime load was higher than the daytime load. Mean arterial pressure (MAP) was higher and heart rates (HR) were faster in the Stage 4-5 group. Conclusions: BP load should be a component employed in ABPM to determine cardiovascular risk stratification. MAP and HR might be associated with risk to develop end-stage renal disease.
\end{abstract}

Copyright (C) 2015 S. Karger AG, Basel

\section{Introduction}

Combined hypertension and chronic kidney disease (CKD) are adult health concerns with a global impact. Both conditions substantially increase the risks of death, cardiovascular 


\section{Kidney \\ Blood Pressure Research}

disease (CVD) and kidney failure [1]. Patient health deteriorates as estimated glomerular filtration rate (eGFR) decreases and $86 \%$ of patients will eventually develop end-stage renal disease (ESRD) [2]. Ambulatory blood pressure monitoring (ABPM) is an effective, noninvasive and portable technique in which blood pressure (BP) is recorded frequently and automatically over an extended period. The typical monitoring is 24 hours. During the testing period, participants continue to take medications and continue normal participation in daily activities.

Diagnoses of hypertension and treatment strategy are usually based on a limited number of daytime clinic BP measurements. However, in large part because of increased sleeping $\mathrm{BP}, \mathrm{BP}$ measured at the clinic supplies an incomplete and potentially misleading evaluation of the severity of hypertension with CKD [3]. The correlation between the magnitude of hemodynamic load or BP level and health concerns such as target-organ damage (TOD) and increased CVD risk is better reflected by ABPM compared to standard clinical BP evaluation [4-6]. Especially relevant finding recorded by ABPM in patients with CKD include the mean, pulse pressure (PP), BP variability (BPV) and circadian changes [5, 7].

Few studies have compared the ambulatory blood pressure (ABP) parameters in patients with combined hypertension and CKD according to CKD stage classification. One general population study [8] demonstrated that eGFR predicted fewer endpoints than systolic BP (SBP) and diastolic BP (DBP) measurements collected by ABPM. Some studies $[9,10]$ have examined ABPM characteristics (including SBP, DBP, PP, BPV and prevalence of the different dipping patterns) according to CKD stage classification, but not BP load, mean arterial pressure (MAP) or heart rate (HR). Other approaches [11-13], however, have demonstrated that BP load, MAP and HR were also important prognostic indicators.

We supposed ABPM was important in combined hypertension and CKD. The purpose of the present study was to improve the diagnosis and treatment of patients with combined hypertension and CKD by observing and comparing ABP parameters and to explore the relationship between $\mathrm{BP}$ changes and renal injury in patients with combined hypertension and CKD.

\section{Materials and Methods}

\section{Patients}

We selected 241 Chinese hypertension in-patients (119 men and 122 women) who were enrolled from November 2011 to October 2014. Among them, 152 patients (78 men and 74 women) were combined hypertension with CKD. Patients maintained a normal daytime activity and nighttime sleep routine given low and the same salt intake. Patients were considered to have hypertension if they were receiving ongoing antihypertensive treatment or if they had SBP/DBP levels that fit the criteria defined by the 2013 European Society of Hypertension-European Society of Cardiology (ESH/ESC) Hypertension Guidelines: ABPM criteria, $24 \mathrm{~h}$ mean SBP/ DBP $\geq 130 / 80 \mathrm{~mm} \mathrm{Hg}$, specifically waking mean SBP/ DBP $\geq 135 / 85 \mathrm{~mm} \mathrm{Hg}$ and/or sleeping mean SBP/DBP $\geq 120 / 70 \mathrm{~mm} \mathrm{Hg}$ [14]. CKD was defined according to the National Kidney Foundation Kidney Disease Outcome Quality Initiative (K/DOQI) guidelines as: (1) kidney damage for $\geq$ three months, as confirmed by kidney biopsy or signs of kidney damage, such as proteinuria, microalbumin, abnormal urinary sediment, or abnormalities on imaging studies, with or without a decrease in eGFR as estimated by the Modification of Diet in Renal Disease (MDRD) formula, or (2) eGFR $<60 \mathrm{~mL} \cdot \mathrm{min}^{-1}$ per $1.73 \mathrm{~m}^{2}$ for $\geq$ three months, with or without kidney damage [15]. The causes of renal disease were glomerulonephritis (n $=73)$, polycystic kidneys $(n=6)$, Sjogren's syndrome $(n=2)$, gouty nephropathy $(n=4)$, interstitial nephritis $(n=1)$, hypertensive nephropathy $(n=39)$, diabetic nephropathy $(n=21)$, lupus nephritis $(n=2)$ and nephrotic syndrome $(n=4)$. Principal exclusion criteria were true pregnancy or lactation, history of drug or alcohol abuse, type 1 diabetes, acquired immunodeficiency syndrome, secondary hypertension (such as primary aldosteronism, pheochromocytoma or Cushing's syndrome), left-hander and big differences BP in left-right arm, and intolerance to ABPM or inability to communicate with others or comply with all study requirements. Patients gave their written informed consent. 


\section{Kidney \\ Blood Pressure Research}

Wu/Wu/Xing/Zhou/Luo/Wang: ABPM in Hypertension Combined CKD

The combined hypertension and CKD patient population was divided according to CKD disease stage and severity. Using the K/DOQI classification, patients were categorized as: (1) stage 1 to 3 (Stage 1-3), moderate kidney damage with elevated GFR (eGFR $\geq 30 \mathrm{~mL} / \mathrm{min} / 1.73 \mathrm{~m}^{2}$ ), 106 patients (56 men and 50women), $59.4 \pm 14.9$ years of age; (2) stage 4 and 5 (Stage 4-5), severe kidney damage with severe reduction in GFR (eGFR $<30 \mathrm{~mL} / \mathrm{min} / 1.73 \mathrm{~m}^{2}$ ) , 46 patients (22 men and 24 women), $60.5 \pm 12.1$ years of age [15].

Clinical Information and Laboratory Data

Clinical information was usually acquired from electronic medical records. A partial list of gathered information includes age, sex, weight, medical history, current medications, treatment with antihypertensive drugs, hypertensive history, laboratory data, clinic BP and HR. Participants reported to the hospital, after eight hours of fasting, between 06:00 and 07:00 in the morning for blood extraction from an antecubital vein. Glucose, serum creatinine, uric acid, blood urea nitrogen, proteinuria, high-density lipoprotein (HDL) cholesterol levels, low-density lipoprotein (LDL) cholesterol levels, albumin, $\beta 2$ micro globulin and other laboratory test values were determined by standard enzymatic methods. The samples were run on automated analyzers in our hospital laboratory using routine automatic techniques.

\section{ABP Measurement}

Twenty-four h ABPM was performed on routine workdays using the ABPM-04 (Meditech Ltd., Budapest, Hungary). Where possible, blood pressure was taken from the left arm and a large size cuff was instead if the arm circumference was larger than 13 inches, and the inflatable bladder's center was placed over the brachial artery. Measurements were made at $20 \mathrm{~min}$ intervals between 07:00 and 22:00 h and every 30 min during the night. At least $70 \%$ of the results during test periods were required to be satisfactory, or else the monitoring was repeated. The patient was instructed to record their sleeping and waking times and follow their normal daily activities and to continue using normal medications, but to refrain from strenuous exercise and keep a similar sleep-activity schedule and avoid daytime napping. At the time of cuff inflation, the patient was instructed to stop moving and talking and to keep the arm still with the cuff at heart level. The measurements were downloaded to the computer and a range of analyses was performed using the ABPM-04 analysis software (Meditech Ltd.).

$\mathrm{ABP}$ was considered normal according to the ESH Working Group on BP Monitoring guidelines if the $24 \mathrm{~h}$ value was 130/80 mm Hg, the daytime value was 135/85 mm Hg and the nighttime value was 120/70 $\mathrm{mm} \mathrm{Hg}$. BP load is the total load of elevated BP values over a $24 \mathrm{~h}$ recording period on cardiovascular system. The area under the curve was 140/90 mmHg during daytime and 120/80 mmHg during nighttime. MAP was calculated as [DBP +1/3 (SBP-DBP)]. PP was calculated as (SBP-DBP). Sleep-time relative BP decline (BP dipping pattern) was defined as [(daytime BP mean - nighttime BP mean) / daytime BP mean] $\times 100 \%$. For nighttime dipping it is generally agreed that a nocturnal SBP fall $\geq 10 \%$ of daytime values will be defined as a "dipper", a nocturnal BP fall $<0 \%$ of daytime values will be defined as a "riser" and all other values will be defined as a "non-dipper" [16]. BPV was calculated as the standard deviation (SD) of the mean daytime and nighttime SBP, DBP and $24 \mathrm{~h}$ BP [17].

\section{Statistical Analysis}

All numerical data are presented as the mean \pm standard deviation (SD) and frequencies (\%) for categorical variables. The distribution of all variables was examined using the Shapiro-Wilk test or Kolmogorov-Smirnov test of normality, and homogeneity of variances was determined using Levene's test. Data were compared between Stage 1-3 and Stage 4-5 groups by an independent-sample Student's $t$ test (continuous variables), or the Mann-Whitney U test for non-parametric data. Comparisons between the daytime and nighttime periods were performed using a paired-samples Student's $t$ test, or a Wilcoxon matched-pairs signed ranks test (a type of nonparametric test) when the data was not normally distributed. The chi-square test was used between groups of dichotomous variables. Statistical analysis was performed using SPSS software (Version 17.0, SPSS Inc., Chicago, IL, USA). Results were considered significant when $p$ $<0.05$. We also compared the proportion of patients between the Stage 1-3 and Stage 4-5 groups with clinic $\mathrm{PP} \geq 65 \mathrm{~mm} \mathrm{Hg}$ and 24-h PP mean > $53 \mathrm{~mm} \mathrm{Hg}$ [18]. 


\section{Kidney \\ Blood Pressure Research}

Table 1. Baseline characteristics of 241 hypertension patients

\begin{tabular}{|c|c|c|c|c|c|}
\hline Variable & $\begin{array}{l}\text { No CKD } \\
(\mathrm{n}=89)\end{array}$ & $\begin{array}{c}\text { Combined } \\
\text { CKD } \\
(n=152)\end{array}$ & $\begin{array}{l}\text { Stage1-3 } \\
(\mathrm{n}=106)\end{array}$ & $\begin{array}{l}\text { Stage } 4-5 \\
(n=46)\end{array}$ & $p$ \\
\hline Number of males ( $\%$ male) & $41(46.1)$ & $78(51.3)$ & $56(52.8)$ & $22(47.8)$ & $0.571 \square$ \\
\hline Diabetes, $\%$ & 16.7 & 22.4 & 21.7 & 23.9 & $0.763 \square$ \\
\hline Age, yrs. & $57.3 \pm 14.7$ & $59.3 \pm 14.3$ & $59.4 \pm 14.9$ & $59.0 \pm 13.2$ & 0.7630 \\
\hline Weight, kg & $66.3 \pm 12.8$ & $65.0 \pm 11.7$ & $66.4 \pm 11.1$ & $62.1 \pm 12.5$ & $0.042 \Delta$ \\
\hline Duration of hypertension, months & $79.9 \pm 98.8$ & $102.2 \pm 101.6$ & $107.7 \pm 110.4$ & $87.5 \pm 74.3$ & $0.805 \circ$ \\
\hline Clinic SBP, mm Hg & $156.4 \pm 27.7$ & $153.3 \pm 24.1$ & $150.3 \pm 21.8$ & $160.1 \pm 27.8$ & $0.036 \Delta$ \\
\hline Clinic DBP, mm Hg & $90.2 \pm 18.6$ & $87.5 \pm 16.4$ & $86.4 \pm 16.2$ & $90.0 \pm 16.5$ & $0.216 \Delta$ \\
\hline Clinic PP, mm Hg & $66.2 \pm 22.4$ & $65.4 \pm 18.9$ & $63.3 \pm 17.8$ & $70.1 \pm 20.6$ & $0.040 \Delta$ \\
\hline Clinic PP $\geq 65 \mathrm{~mm} \mathrm{Hg}, \%$ & 48.3 & 41.4 & 34.9 & 56.5 & $0.013 \square$ \\
\hline Clinic HR, beats/min & $80.5 \pm 14.5$ & $79.8 \pm 11.9$ & $79.3 \pm 11.6$ & $81.1 \pm 12.6$ & $0.454 \circ$ \\
\hline Fasting blood-glucose, mmol/L & $5.5 \pm 2.2$ & $5.2 \pm 1.7$ & $5.3 \pm 1.9$ & $4.9 \pm 1.3$ & $0.090 \circ$ \\
\hline Serum creatinine, $\mu \mathrm{mol} / \mathrm{L}$ & $66.9 \pm 15.5$ & $241.7 \pm 291.8$ & $109.7 \pm 38.7$ & $546.0 \pm 382.7$ & $<0.0010$ \\
\hline Blood urea nitrogen, $\mathrm{mmol} / \mathrm{L}$ & $4.8 \pm 1.5$ & $10.9 \pm 7.8$ & $7.3 \pm 2.7$ & $19.1 \pm 9.3$ & $<0.0010$ \\
\hline Uric acid, $\mu \mathrm{mol} / \mathrm{L}$ & $338.2 \pm 104.4$ & $428.0 \pm 116.7$ & $412.9 \pm 113.3$ & $463.2 \pm 118.0$ & $0.014 \Delta$ \\
\hline Total cholesterol, mmol/L & $4.6 \pm 1.0$ & $4.7 \pm 1.5$ & $4.8 \pm 1.6$ & $4.5 \pm 1.4$ & $0.367 \circ$ \\
\hline Triglycerides, mmol/L & $1.8 \pm 2.0$ & $1.7 \pm 1.0$ & $1.8 \pm 1.0$ & $1.6 \pm 0.9$ & $0.149 \circ$ \\
\hline HDL cholesterol, $\mathrm{mmol} / \mathrm{L}$ & $1.2 \pm 0.3$ & $1.2 \pm 0.4$ & $1.2 \pm 0.3$ & $1.3 \pm 0.5$ & 0.9510 \\
\hline LDL cholesterol, mmol/L & $2.5 \pm 0.7$ & $2.5 \pm 1.0$ & $2.6 \pm 1.0$ & $2.3 \pm 0.8$ & $0.048 \circ$ \\
\hline Hemoglobin, g/L & $131.4 \pm 17.1$ & $115.9 \pm 21.3$ & $123.1 \pm 19.8$ & $99.3 \pm 14.4$ & $<0.001 \Delta$ \\
\hline Albumin, g/L & $40.4 \pm 4.3$ & $38.8 \pm 6.9$ & $39.5 \pm 6.7$ & $37.3 \pm 7.0$ & $0.005 \circ$ \\
\hline Average urine protein, $\mathrm{g} / \mathrm{d}$ & $0.1 \pm 0.1$ & $1.0 \pm 1.3$ & $0.9 \pm 1.0$ & $1.9 \pm 1.8$ & $<0.001 \circ$ \\
\hline Proteinuria, mg/L & $73.6 \pm 81.4$ & $670.7 \pm 680.1$ & $522.9 \pm 600.5$ & $1119.3 \pm 720.7$ & $<0.0010$ \\
\hline$\beta 2$ microglobulin, mg/L & & $11.1 \pm 22.0$ & $4.1 \pm 2.3$ & $22.7 \pm 33.0$ & $<0.0010$ \\
\hline$\alpha 1$ microglobulin mg/dL & $1.0 \pm 1.2$ & $5.0 \pm 10.3$ & $3.0 \pm 3.3$ & $11.3 \pm 19.1$ & $<0.001 \circ$ \\
\hline Microalbumin, mg/dL & $2.3 \pm 3.9$ & $75.4 \pm 108.4$ & $63.3 \pm 98.1$ & $112.4 \pm 130.4$ & $0.004 \circ$ \\
\hline $\begin{array}{l}\text { Estimated glomerular filtration } \\
\text { rate, } \mathrm{mL} / \mathrm{min} / 1.73 \mathrm{~m}^{2}\end{array}$ & $101.2 \pm 18.1$ & $49.5 \pm 32.2$ & $64.5 \pm 26.2$ & $14.0 \pm 8.6$ & $<0.001 \circ$ \\
\hline
\end{tabular}

Values are shown as mean \pm SD. The p-values stand for a comparison between the two groups by stage of CKD. $\square$ : The $p$ value was obtained by Pearson chi-square test. $\circ$ : The $p$ value was obtained by Mann-Whitney U test (a type of nonparametric test), which was used here due to the data not being normally distributed. $\Delta$ : The $p$ value was obtained by independent-samples Student's $t$ test.

\section{Results}

\section{Baseline characteristics}

Baseline characteristics of the 241 hypertension patients are presented in Table1. Onehundred and six participants (69.7\%) with combined hypertension and CKD had an eGFR of $\geq 30 \mathrm{ml} / \mathrm{min} / 1.73 \mathrm{~m}^{2}$ and 46 (30.3\%) participants had an eGFR $<30 \mathrm{ml} / \mathrm{min} / 1.73 \mathrm{~m}^{2}$. Most baseline characteristics were similar in the Stage 1-3 and Stage 4-5 groups. The Stage 4-5 group had higher clinic SBP, PP, serum creatinine, blood urea nitrogen, uric acid, proteinuria, average urine protein, $\beta 2$ microglobulin, $\alpha 1$ microglobulin and microalbumin levels, but lower weight, LDL cholesterol, albumin and hemoglobin $(p<0.05)$. The percentage of patients with clinic $\mathrm{PP} \geq 65 \mathrm{~mm} \mathrm{Hg}$, and thus at relatively greater risk of CVD morbidity and mortality [18], was significantly higher among patients in the Stage 4-5 group $(p<0.05)$. 


\section{Kidney Bloód Pressure Research}

Fig. 1. Circadian patterns of mean SBP (up) and DBP (down) in mmHg of with c o m b i n e d CKD (continuous line) and no CKD (dashed line) assessed by 24-h ABPM. Each graph shows hourly means of data for each group of patients. Abbreviation: SBP, systolic blood pressure; DBP, diastolic blood pressure; CKD, chronic kidney disease; ABPM, a mbulatory blood pressure monitoring.

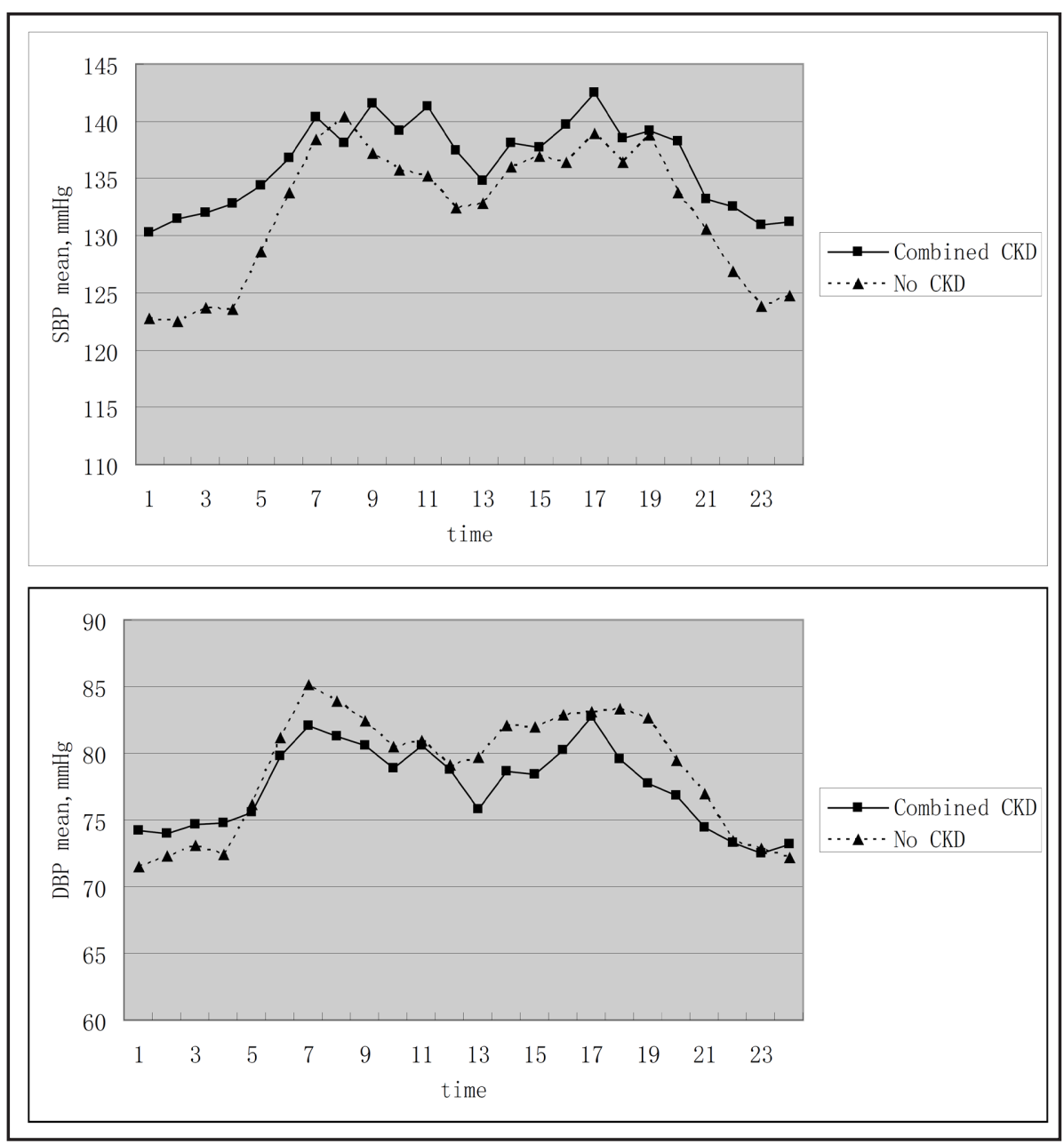

\section{ABPM Characteristics of hypertension Patients}

Figure 1 shows the 24-h patterns of SBP (up) and DBP (down) for hypertension patients without CKD and with combined hypertension and CKD assessed by 24-h ABPM. Sleep-time relative BP declines were significantly differed between the hypertension patients without CKD and with combined hypertension and CKD $(p<0.05)$.

The proportion of patients with a $24 \mathrm{~h}$ PP mean $>53 \mathrm{~mm} \mathrm{Hg}$ significantly differed between the Stage 1-3 and Stage 4-5 groups, $79.5 \%$ in the Stage 4-5 group as opposed to $54.3 \%$ in the Stage 1-3 group ( $p<0.05$ ). The prevalence of non-dipping rhythm was quite high $(78.3 \%)$ in patients with combined hypertension and CKD and increased with the deterioration of renal function $(73.6 \%$ vs. $89.1 \%)$.

The differences between daytime, nighttime and 24 h mean SBPs, DBPs, SBP load, DBP load, HR, PP, MAP and daytime and $24 \mathrm{~h}$ SBP SD between the two groups were higher in the Stage $4-5$ group $(p<0.05)$ (Figure $2-4)$. The SBP and DBP loads were higher during the nighttime than during the daytime period $(p<0.001)$ (Figure 2 and 3). Figure 5 illustrated the area under the curve of the Stage 1-3 and 4-5 groups. The proportion of patients with the riser BP rhythm, and thus the highest CVD risk, increased from $26.4 \%$ in the Stage $1-3$ group to $34.8 \%$ in the Stage 4-5 group (Figure 6). Nighttime SBP SD, DBP SD, HR SD and HR relative decline in time asleep were similar between the two groups. 


\section{Kidney Blood Pressure Research}

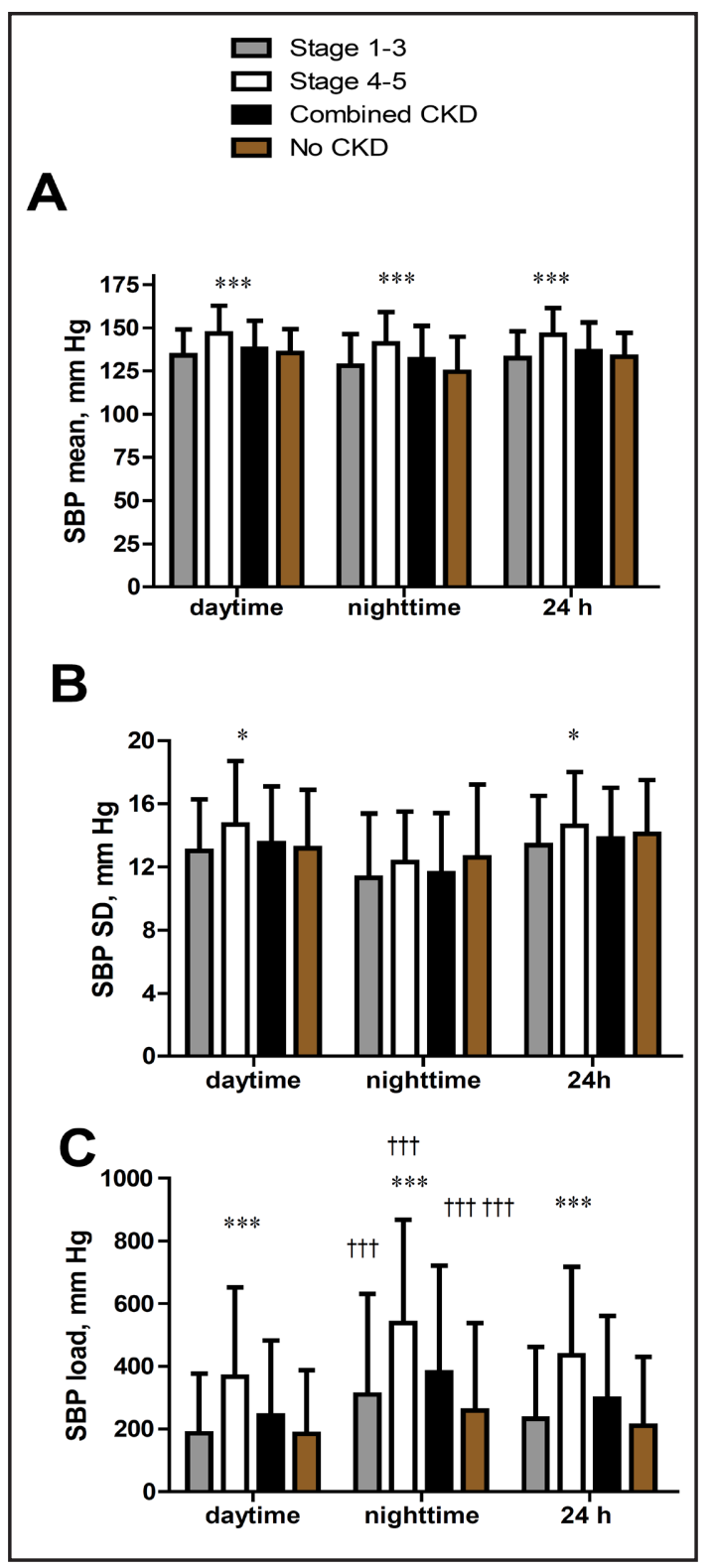

Fig. 2. Changes in daytime, nighttime and $24 \mathrm{~h} \mathrm{SBP}$ mean (A), SD (B) and load (C) of hypertension patients and displayed as patients in the Stage 1-3, Stage 4-5, combined CKD and no CKD groups. ${ }^{*} P<0.05$, ${ }^{* *} p \leq 0.01,{ }^{* * *} p \leq 0.001$ vs. the Stage 1-3 group. 什 $p \leq 0.001$ vs. daytime load. Abbreviation: SBP, systolic blood pressure; CKD, chronic kidney disease.

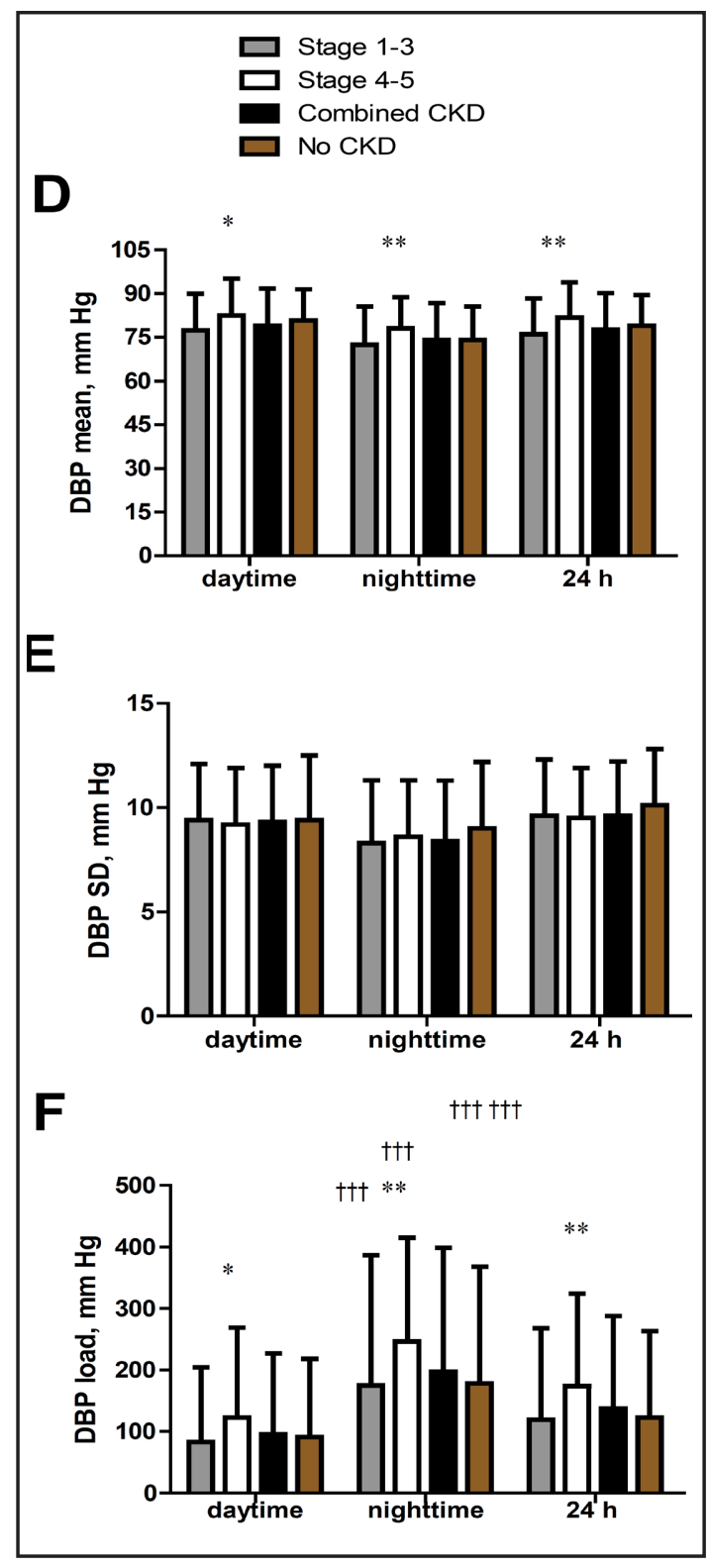

Fig. 3. Changes in daytime, nighttime and $24 \mathrm{~h} \mathrm{DBP}$ means (D), SD (E) and load (F) of hypertension patients and displayed as patients in the Stage 1-3, Stage 4-5, combined CKD and no CKD groups. $* P<0.05$, ** $p \leq 0.01$ vs. the Stage 1-3 group. †十† $p \leq 0.001$ vs. daytime load. Abbreviation: DBP, diastolic blood pressure; CKD, chronic kidney disease.

\section{Discussion}

The present study discloses that the Stage 4-5 group displayed an increased prevalence of CVD risk factor markers. Patients in the Stage 4-5 group had higher serum creatinine, blood urea nitrogen, uric acid, proteinuria, average urine protein, $\beta 2$ microglobulin, $\alpha 1$ microglobulin and microalbumin than patients in the Stage 1-3 group. Additionally, clinic 


\section{Kidney Blood Pressure Research}

Kidney Blood Press Res 2015;40:478-489

DOI: 10.1159/000368525

Published online: September 30, 2015

(c) 2015 S. Karger AG, Basel

www.karger.com/kbr

484
SBP was significantly higher in patients in the Stage 4-5 group. Poorly controlled BP accelerates the decline in kidney function due to CKD, while good control slows the progression [19]. Hence, early treatment of hypertension is necessary in patients with CKD. Finally, there were marked differences between the general population, patients with hypertension, and patients with combined hypertension and CKD in clinic PP, indicating that there is stiffness in the major arteries in patients with combined hypertension and CKD [18].

Our study also observed highly significant differences in $24 \mathrm{~h}$ BP regulation between the Stage 1-3 and Stage 4-5 groups. The levels of daytime, nighttime and $24 \mathrm{~h}$ mean SBPs and DBPs were higher in the Stage 4-5 group. Elevated BP has been associated with an increased risk of ESRD incidence with an eGFR $<60 \mathrm{ml} / \mathrm{min} / 1.73 \mathrm{~m}^{2}$ [12, 20, 21]. Recent trials documented that elevated BP, particularly SBP, contributed to declining kidney function and further reported that SBP was a better predictor of adverse renal and cardiovascular outcomes than ambulatory DBP values $[7,21]$. Similarly, we observed that SBP was more significantly different between the Stage 1-3 and Stage 4-5 groups when compared with DBP. BPV has been used to assess the features of cardiovascular control mechanisms. Recent data demonstrated that BPV, particularly waking SBP variability, might be positively associated with LVH and TOD in hypertensive CKD patients [10, 22]. In this study, BPV was calculated as the standard deviation (SD) of the mean daytime and nighttime SBP, DBP and 24 $h \mathrm{BP}$, and we observed that daytime and $24 \mathrm{~h}$ SBP SD were higher in the Stage 4-5 group.

The loss of nocturnal BP decline is common in CKD, and blunted BP decline at night has been associated with TOD and CVD $[7,16]$. Our study also indicates that the prevalence of an abnormal circadian BP rhythm (non-dipping rhythm) was quite high in CKD patients and increased with the deterioration of renal function. We also found a significant progressive increase in the prevalence of non-dippers and risers across the categories of decreasing eGFR that define the

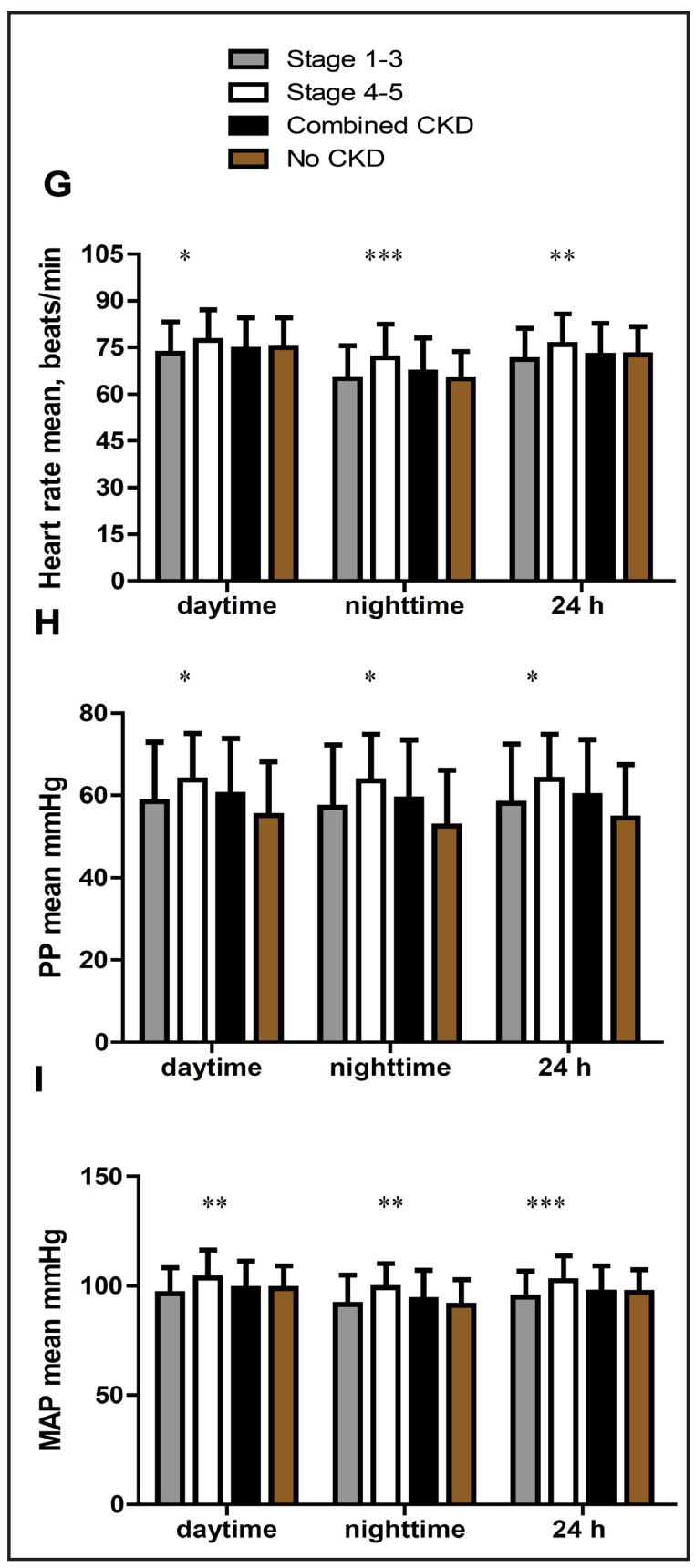

Fig. 4. Changes in daytime, nighttime and $24 \mathrm{~h}$ means of HR (G), PP (H) and MAP (I) in hypertension patients and displayed as patients in the Stage $1-3$, Stage $4-5$, combined CKD and no CKD groups. ${ }^{*} P<0.05,{ }^{* *} p \leq 0.01$, *** $p \leq 0.001$ vs. the Stage 1-3 group. Abbreviation: HR, heart rates; PP, pulse pressure; MAP, mean arterial pressure; CKD, chronic kidney disease. 


\section{Kidney \\ Blood Pressure Research}

stages of CKD. Minutolo et al. [23] suggested that non-dipper patients with CKD receiving antihypertensive therapy to decrease nocturnal BP and proteinuria had a significantly worse long-term outcome and increased cardiovascular risk.

BP load was first introduced by Zachariah et al. [24] and White et al. [25] Zachariah et $a$. [24] defined BP load as the percentage of BP values exceeding a given constant threshold. White et al. [25] suggested that elevated $\mathrm{BP}$ values during the waking hours $(\geq \quad 140 / 90$ $\mathrm{mm} \mathrm{Hg}$ ) and sleeping hours ( $\geq 120 / 80 \mathrm{~mm}$ $\mathrm{Hg}$ ) could be used to calculate the total percentage of every abnormal BP value (load) in each patient. White et al. [25] proposed that BP load acquired from $24 \mathrm{~h}$
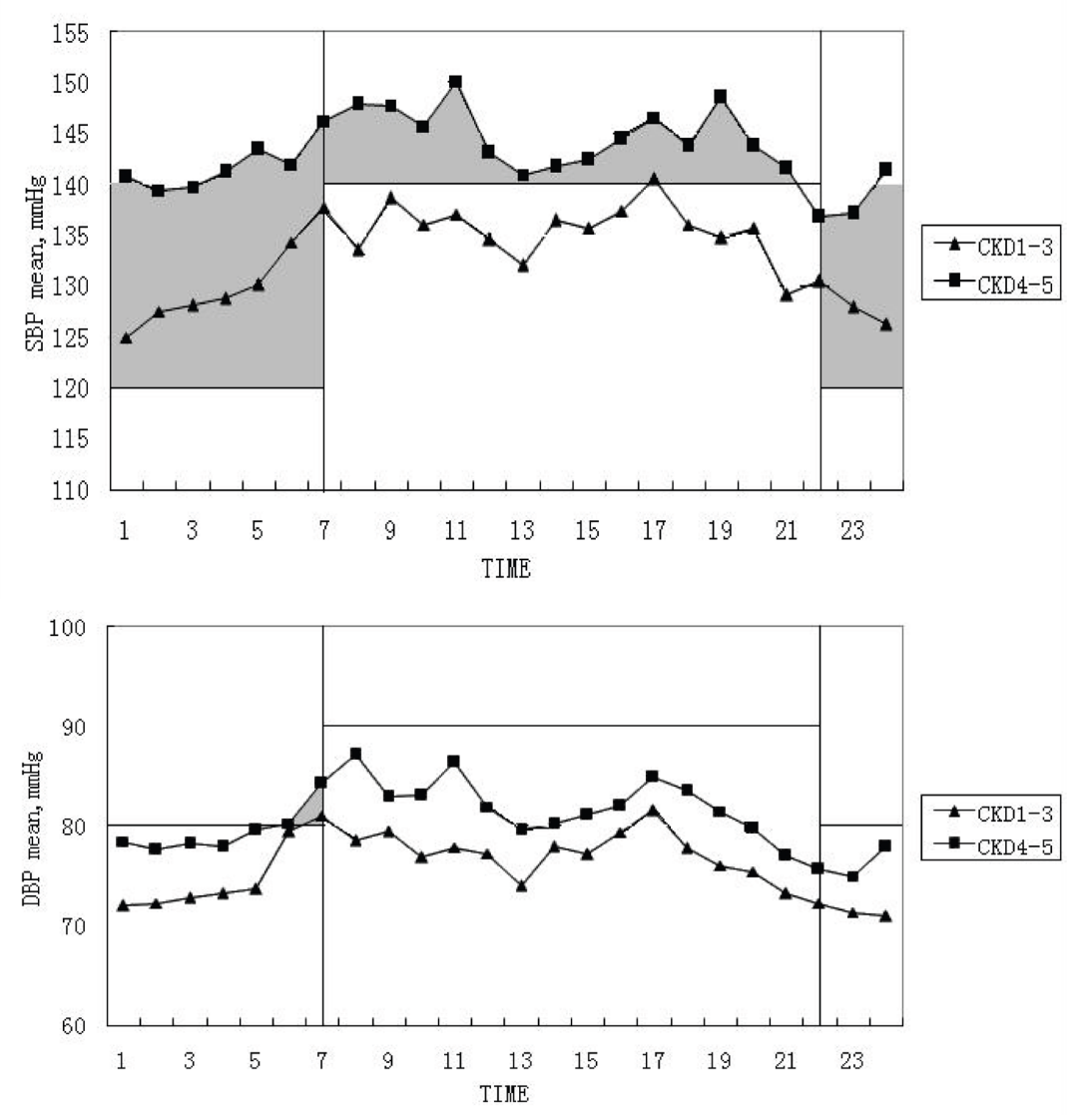

Fig. 5. The SBP (up) and DBP (down) load calculated from the area under the curve of the Stage 1-3 and 4-5 groups. Abbreviation: SBP, systolic blood pressure; DBP, diastolic blood pressure.

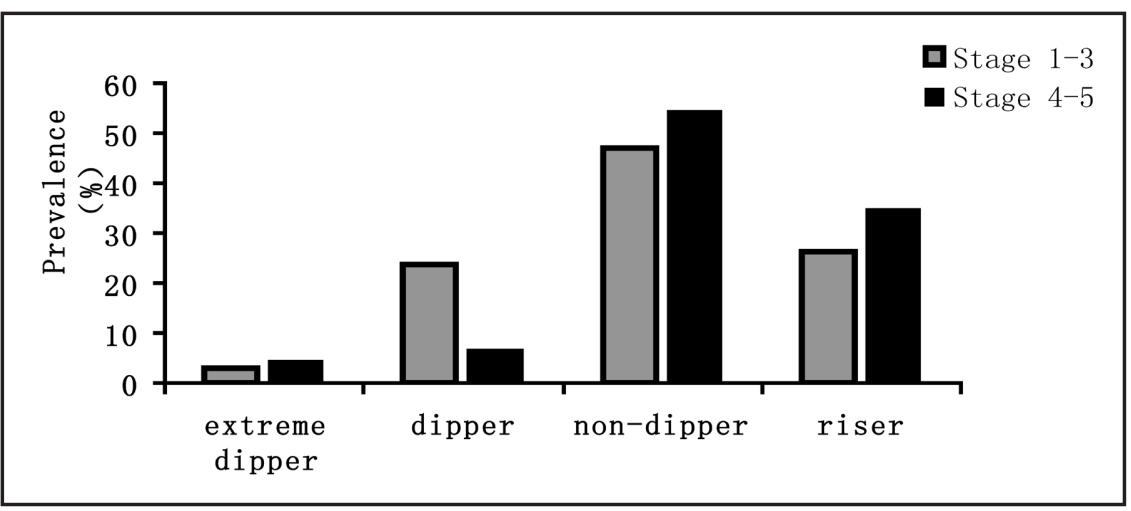

Fig. 6. Prevalence of the different circadian patterns of patients with combined hypertension and CKD in the Stage 1-3 and Stage 4-5 groups. Dipping classification was determined according to the value of the relative SBP decline during sleep-time. Extreme dippers, nocturnal SBP reduction $\geq 20 \%$; dippers, $10-20 \%$ reduction; non-dippers, 0 - 10\% reduction; and risers, < $0 \%$ reduction. Abbreviation: CKD, chronic kidney disease. 


\section{Kidney Blood Pressure Research}

Kidney Blood Press Res 2015;40:478-489

\begin{tabular}{l|l}
\hline DOI: $10.1159 / 000368525$ & (C) 2015 S. Karger AG, Basel
\end{tabular}

Published online: September 30, 2015

www.karger.com/kbr

486

ABPM recordings could be a more accurate predictor of renal and cardiovascular outcomes than BP level, especially in normotensive people, and successfully used BP load to assess cardiac risk in a group of 30 previously untreated patients with mild-to-moderate essential hypertension. Additionally, Liu et al. [26] recruited 869 individuals referred for $24 \mathrm{~h}$ ABPM and found that BP load was associated with TOD, but not independently of BP level. Microalbuminuria was associated with a greater systemic BP load and increased vascular permeability in patients with primary hypertension [27]. Another study of this kind [11] suggested that, in patients with mild-to-moderate arterial hypertension, a high $24 \mathrm{~h} \mathrm{SBP}$ load might be associated, independently of the average $24 \mathrm{~h}$ ambulatory SBP, with an adverse cardiovascular risk profile. BP load could be used to diagnose hypertension during pregnancy if calculated with reference to BP limits that should be markedly below the currently accepted thresholds of normotension in pregnancy and that are defined in relation to predictable trends in BP according to gestational age and rest-activity cycle [28]. Other authors have suggested that BP load might be more relevant than diurnal and nocturnal mean BP and dipping [29].

This is the first study to compare $24 \mathrm{~h} \mathrm{ABPM}$ with BP load in patients with combined hypertension and CKD. This study indicates that the levels of daytime, nighttime and $24 \mathrm{~h}$ SBP load and nighttime and $24 \mathrm{~h}$ DBP load were higher in stage 4-5 CKD. Another important finding of our study is that nighttime SBP and DBP loads are higher than the corresponding daytime loads. Consequently, these patients' veins are under high load pressure for an extended time, and this prolonged pressure can induce changes in microcirculation structures that will eventually cause TOD. However, BP load is not usually presented in an ABPM report. In light of the results of our study, we suggest that BP load ought to be included as a standard component of ABPM for cardiovascular risk stratification and that hypertension medications should be selected to reduce nighttime BP load.

In previous cross-sectional studies on hypertensive CKD patients $[12,18]$, PP might have the strongest association with ESRD and the incidence of death among individuals with reduced eGFR [9], as well as an established ability to predict cardiovascular morbidity and mortality [30]. Our data show that daytime, nighttime and $24 \mathrm{~h}$ mean PP and MAP were higher with increasing CKD severity. The proportion of patients with a $24 \mathrm{~h}$ PP mean $>53$ $\mathrm{mm} \mathrm{Hg}$ was significantly higher in the Stage 4-5 group. In the African-American Study of Kidney Disease trial, Wright et al. [31] found that, among patients with hypertensive renal disease (eGFR, $20-65 \mathrm{ml} / \mathrm{min} / 1.73 \mathrm{~m}^{2}$ ), participants randomized to MAP goals of 102 107 or to $92 \mathrm{~mm} \mathrm{Hg}$ or less had similar frequencies of renal function decline. Among 840 participants with various levels of CKD severity in the MDRD study, the rate of decline in renal function was similar among patients randomized to a MAP $<92 \mathrm{~mm} \mathrm{Hg}$ vs. $<107 \mathrm{~mm}$ Hg. Daytime, nighttime and $24 \mathrm{~h}$ MAP were similar between the normal and mildly impaired renal function groups [32]. However, it was previously demonstrated that MAP might have an association with ESRD incidence among patients with reduced eGFR. The incidence rate of ESRD was increased at higher levels of SBP, DBP, PP and MAP in adults with CKD [12]. In our study, MAP was higher in the Stage 4-5 CKD group.

Aono et al. [33] showed that there was no significant difference in mean HR between the hypertensive and normotensive group. However, we found that daytime, nighttime and $24 \mathrm{~h}$ HR were faster in the Stage 4-5 group. The kidney is densely innervated by sympathetic and sensory fibers and can be both a target of sympathetic activity and a source of signals driving sympathetic tone. Increases in HR are directly related to sympathetic nervous system overactivity and increased risk of TOD [34]. In a 48 h Holter ECG study of 407 normotensive ESRD patients, Cice et al. [35] found that increased mean HR had an independent association with cardiovascular mortality. Xu et al. [36] indicated that a new hormone, renalase, secreted by kidney and circulating in blood, reduced degradation of catecholamines. Renalase administered intravenously to Sprague-Dawley rats caused a decrease in HR by $25 \%$.

Our study has compared the ABP parameters including SBP, DBP, PP, BPV and prevalence of the different dipping patterns especially BP load, MAP or HR in patients with combined 


\section{Kidney \\ Blood Pressure Research}

hypertension and CKD according to CKD stage classification. The present study confirmed the greater relationship of ABPM with renal insufficiency including patients with very low GFR.

\section{Limitations}

We acknowledge that the current study has a few limitations. First, our sample size was very small. However, our extensive exclusion criteria controlled for many confounding variables that could have influenced renal function. Second, this study is a retrospective investigation; therefore, we cannot conclude that there are causal links between the BP index and the patients' prognosis. Future research is therefore needed to establish this causal relationship and further develop ABPM based diagnosis and treatment determination of CKD.

\section{Conclusions}

We evaluated patients with combined hypertension and CKD by $24 \mathrm{~h}$ ABPM and demonstrated that the levels of daytime, nighttime and $24 \mathrm{~h} \mathrm{SBP}$ and DBP loads were higher in the Stage 4-5 CKD group. Additionally, we demonstrated that the nighttime SBP and DBP loads were higher than the daytime load. Therefore, we suggest that BP load should be a component employed in ABPM to determine cardiovascular risk stratification and select hypertension medications designed to reduce nighttime BP load. MAP, which is associated with the risk of developing ESRD, was higher in the Stage 4-5 group in our study. Moreover, elevated HR is also associated with the development of ESRD and cardiovascular mortality, and we found that daytime, nighttime and $24 \mathrm{~h}$ HR were faster in the Stage 4-5 group.

\section{Disclosure Statement}

The authors have no funding, financial relationships, or conflicts of interest to disclose.

\section{Acknowledgement}

We thank Medjaden Bioscience Limited for assisting in the preparation of this manuscript. This work was performed primarily at Ningbo Beilun People's Hospital. This work was supported by the Natural Science Foundation of Zhejiang Province (No. LY15H020006), the foundation from Zhejiang Provincial Department of Health (No. 2009B060) and Zhejiang Provincial Administration of traditional Chinese Medicine (No. 2011ZQ013). The corresponding author is sponsored by Zhejiang Provincial Program for the Cultivation of High-level Innovative Health talents.

\section{References}

1 Sarnak MJ, Levey AS, Schoolwerth AC, Coresh J, Culleton B, Hamm LL, McCullough PA, Kasiske BL, Kelepouris E, Klag MJ, Parfrey P, Pfeffer M, Raij L, Spinosa DJ, Wilson PW; American Heart Association Councils on Kidney in Cardiovascular Disease, High Blood Pressure Research, Clinical Cardiology, and Epidemiology and Prevention: Kidney disease as a risk factor for development of cardiovascular disease: a statement from the American Heart Association Councils on Kidney in Cardiovascular Disease, High Blood Pressure Research, Clinical Cardiology, and Epidemiology and Prevention. Circulation 2003;108:21542169. 


\section{Kidney \\ Blood Pressure Research}

2 Agarwal R, Nissenson AR, Battle D, Coyne DW, Trout JR, Warnock DG: Prevalence, treatment, and control of hypertension in chronic hemodialysis patients in the United States. Am J Med 2003;115:291-297.

3 Pogue V, Rahman M, Lipkowitz M, Toto R, Miller E, Faulkner M, Rostand S, Hiremath L, Sika M, Kendrick C, Hu B, Greene T, Appel L, Phillips RA: African American Study of Kidney Disease and Hypertension Collaborative Research Group: Disparate Estimates of Hypertension Control From Ambulatory and Clinic Blood Pressure Measurements in Hypertensive Kidney Disease. Hypertension 2009;53:20-27.

4 O’Brien E, Asmar R, Beilin L, Imai Y, Mallion JM, Mancia G, Mengden T, Myers M, Padfield P, Palatini P, Parati G, Pickering T, Redon J, Staessen J, Stergiou G, Verdecchia P: European Society of Hypertension Working Group on Blood Pressure Monitoring: European Society of Hypertension recommendations for conventional, ambulatory and home blood pressure measurement. J Hypertens 2003;21:821-848.

5 Gabbai FB, Rahman M, Hu B, Appel LJ, Charleston J, Contreras G, Faulkner ML, Hiremath L, Jamerson KA, Lea JP, Lipkowitz MS, Pogue VA, Rostand SG, Smogorzewski MJ, Wright JT, Greene T, Gassman J, Wang X, Phillips RA: Relationship between Ambulatory BP and Clinical Outcomes in Patients with Hypertensive CKD. Clin J Am Soc Nephrol 2012;7:1770-1776.

6 Ghuman N, Campbell P, White WB: Role of Ambulatory and Home Blood Pressure Recording in clinical practice. Curr Cardiol Rep 2009;11:414-421.

7 Minutolo R, Agarwal R, Borrelli S, Chiodini P, Bellizzi V, Nappi F, Cianciaruso B, Zamboli P, Conte G, Gabbai FB, De Nicola L: Prognostic role of ambulatory blood pressure measurement in patients with nondialysis chronic kidney disease. Arch Intern Med 2011;171:1090-1098.

8 Boggia J, Thijs L, Li Y, Hansen TW, Kikuya M, Björklund-Bodegård K, Ohkubo T, Jeppesen J, Torp-Pedersen C, Dolan E, Kuznetsova T, Stolarz-Skrzypek K, Tikhonoff V, Malyutina S, Casiglia E, Nikitin Y, Lind L, Schwedt E, Sandoya E, Kawecka-Jaszcz K, Filipovsky J, Imai Y, Wang J, Ibsen H, O'Brien E, Staessen JA; International Database on Ambulatory blood pressure in relation to Cardiovascular Outcomes (IDACO) Investigators: Risk Stratification by 24-Hour Ambulatory Blood Pressure and Estimated Glomerular Filtration Rate in 5322 Subjects From 11 Populations. Hypertension 2013;61:18-26.

9 Mojón A, Ayala DE, Piñeiro L, Otero A, Crespo JJ, Moyá A, Bóveda J, de Lis JP, Fernández JR, Hermida RC; Hygia Project Investigators: Comparison of Ambulatory Blood Pressure Parameters of Hypertensive Patients With and Without Chronic Kidney Disease. Chronobiology Int 2013;30:145-158.

10 Ryu J, Cha RH, Kim DK, Lee JH, Yoon SA, Ryu DR, Oh JE, Kim S, Han SY, Lee EY, Kim YS; APrODiTe investigators: The Clinical Association of the Blood Pressure Variability with the Target Organ Damage in Hypertensive Patients with Chronic Kidney Disease. J Korean Med Sci 2014;29:957-964.

11 Mulè G, Nardi E, Andronico G, Cottone S, Raspanti F, Piazza G, Volpe V, Ferrara D, Cerasola G: Relationships between $24 \mathrm{~h}$ blood pressure load and target organ damage in patients with mild-to-moderate essential hypertension. Blood Press Monit 2001;6:115-123.

12 Bell EK, Gao L, Judd S, Glasser SP, McClellan W, Gutiérrez OM, Safford M, Lackland DT, Warnock DG, Muntner P: Blood Pressure Indexes and End-Stage Renal Disease Risk in Adults With Chronic Kidney Disease. Am J Hypertens 2012;25:789-796.

13 Kikuya M, Hozawa A, Ohokubo T, Tsuji I, Michimata M, Matsubara M, Ota M, Nagai K, Araki T, Satoh H, Ito S, Hisamichi S, Imai Y: Prognostic significance of blood pressure and heart rate variabilities. The Ohasama Study. Hypertension 2000;36:901-906.

14 Mancia G, Fagard R, Narkiewicz K, Redón J, Zanchetti A, Böhm M, Christiaens T, Cifkova R, De Backer G, Dominiczak A, Galderisi M, Grobbee DE, Jaarsma T, Kirchhof P, Kjeldsen SE, Laurent S, Manolis AJ, Nilsson PM, Ruilope LM, Schmieder RE, Sirnes PA, Sleight P, Viigimaa M, Waeber B, Zannad F; Task Force Members: 2013 ESH/ESC Guidelines for the management of arterial hypertension: The Task Force for the management of arterial hypertension of the European Society of Hypertension (ESH) and of the European Society of Cardiology (ESC). J Hypertens 2013;34:2159-2219.

15 National Kidney Foundation: K/DOQI clinical practice guidelines for chronic kidney disease: evaluation, classification, and stratification. Am J Kidney Dis 2002;39:S1-S266.

16 de la Sierra A, Redon J, Banegas JR, Segura J, Parati G, Gorostidi M, de la Cruz JJ, Sobrino J, Llisterri JL, Alonso J, Vinyoles E, Pallarés V, Sarría A, Aranda P, Ruilope LM; Spanish Society of Hypertension Ambulatory Blood Pressure Monitoring Registry Investigators: Prevalence and Factors Associated With Circadian Blood Pressure Patterns in Hypertensive Patients. Hypertension 2009;53:466-472. 


\section{Kidney \\ Bloód Pressure Research}

Kidney Blood Press Res 2015;40:478-489

\begin{tabular}{l|l}
\hline DOI: $10.1159 / 000368525$ & (C) 2015 S. Karger AG, Basel
\end{tabular}

Published online: September 30, 2015

www.karger.com/kbr

17 Parati G: Blood pressure variability: its measurement and significance in hypertension. J Hypertens 2005;23:S19-S25.

18 Verdecchia P, Schillaci G, Borgioni C, Ciucci A, Pede S, Porcellati C: Ambulatory pulse pressure: a potent predictor of total cardiovascular risk in hypertension. Hypertension 1998;32:983-988.

19 National Blood Pressure Education Program. National Blood Pressure Education Program Working Group report on hypertension and chronic renal failure. Arch Intern Med 1991;151:1280-1287.

20 Agarwal R, Bunaye Z, Bekele DM, Light RP: Competing risk factor analysis of endstage renal disease and mortality in chronic kidney disease. Am J Nephrol 2008;28:569-575.

21 Rifkin DE, Katz R, Chonchol M, Shlipak MG, Sarnak MJ, Fried LF , Newman AB , Siscovick DS , Peralta CA : Blood pressure components and decline in kidney $\mathrm{f}$ unction in community-living older adults: the Cardiovascular Health Study. Am J Hypertens 2013;26:1037-1044.

22 Tatasciore A, Renda G, Zimarino M, Soccio M, Bilo G, Parati G, Schillaci G, Caterina RD: Awake Systolic Blood Pressure Variability Correlates With Target-Organ Damage in Hypertensive Subjects. Hypertension 2007;50:325-332.

23 Minutolo R, Gabbai FB, Borrelli S, Scigliano R, Trucillo P, Baldanza D , Laurino S, Mascia S , Conte G, De Nicola L: Changing the timing of antihypertensive therapy to reduce nocturnal blood pressure in CKD: an 8-week uncontrolled trial. Am J Kidney Dis 2007;50:901-903.

24 Zachariah PK, Sheps SG, Ilstrup DM, Long CR, Bailey KR, Wiltgen CM, Carlson CA: Blood pressure load - a better determinant of hypertension. Mayo Clin Proc 1988;63:1085-1091.

25 White WB, Dey HM, Schulman P: Assessment of the daily blood pressure load as a determinant of cardiac function in patients with mild-to-moderate hypertension. Am Heart J 1989;118:782-795.

26 Liu M, Li Y, Wei FF, Zhang L, Han JL, Wang JG: Is blood pressure load associated, independently of blood pressure level, with target organ damage? J Hypertens 2013;31:1812-1818.

27 Viazzi F, Leoncini G, Ratto E, Vaccaro V, Tomolillo C, Falqui V, Parodi A, Conti N, Deferrari G, Pontremoli R: Microalbuminuria, Blood Pressure Load, and Systemic Vascular Permeability in Primary Hypertension. Am J Hypertens 2006;19:1183-1189.

28 Hermida RC, Ayala DE: Evaluation of the Blood Pressure Load in the Diagnosis of Hypertension in Pregnancy. Hypertension 2001;38:723-729.

29 Leenen FH, Coletta E, Davies RA: Prevention of renal dysfunction and hypertension by amlodipine after heart transplant. Am J Cardiol 2007;100:531-535.

30 Wang Y, Hu Y, Li Y, Li H, Chu S, Zhu D, Gao P: Association of renal function with the ambulatory arterial stiffness index and pulse pressure in hypertensive patients. Hypertens Res 2012;35:201-206.

31 Wright JT Jr, Bakris G, Greene T, Agodoa LY, Appel LJ, Charleston J, Cheek D, Douglas-Baltimore JG, Gassman J, Glassock R, Hebert L, Jamerson K, Lewis J, Phillips RA, Toto RD, Middleton JP, Rostand SG, African American Study of Kidney Disease and Hypertension Study Group: Effect of blood pressure lowering and antihypertensive drug class on progression of hypertensive kidney disease: results from the AASK trial. JAMA 2002;288:2421-2431.

32 Klahr S, Levey AS, Beck GJ, Caggiula AW, Hunsicker L, Kusek JW, Striker G: The effects of dietary protein restriction and blood-pressure control on the progression of chronic renal disease. Modification of Diet in Renal Disease Study Group. N Engl J Med 1994;330:877-884.

33 Aono T, Sato T, Nishinaga M, Kawamoto A, Ozawa T: Power and Spectral Analysis of Heart Rate Variabilit Spontaneousy in Elderly Blood Pressure Hypertensives. Hypertens Res 1996;19:9-16.

34 Kanaoka T, Tamura K, Ohsawa M, Yanagi M, Haku S, Wakui H, Maeda A, Dejima T, Azushima K, Mitsuhashi H, Okano Y, Fujikawa T, Toya Y, Mizushima S, Tochikubo O, Umemura S: Relationship of ambulatory blood pressure and the heart rate profile with renal function parameters in hypertensive patients with chronic kidney disease. Clin Exp Hypertens 2012;34:264-249.

35 Cice G, Di Benedetto A, D'Andrea A, D'Isa S, De Gregorio P, Marcelli D, Gatti E, Calabrò R: Heart rate as independent prognostic factor for mortality in normotensive hemodialysed patients. J Nephrol 2008;21:704-712.

36 Xu J, Li G, Wang P, Velazquez H, Yao X, Li Y, Wu Y, Peixoto A, Crowley S, Desir GV: Renalase is a novel, soluble monoamine oxidase that regulates cardiac function and blood pressure. J Clin Invest 2005;115:1275-1280. 